\title{
Construction of deep-blue AIE luminogens with TPE and oxadiazole units
}

\author{
HUANG Jing ${ }^{1}$, CHEN PengYu ${ }^{1}$, YANG Xiao ${ }^{2}$, TANG RunLi $^{1}$, WANG Lei ${ }^{2 *}$, \\ QIN JinQui ${ }^{1} \&$ LI Zhen ${ }^{1 *}$
}

1 Department of Chemistry, Wuhan University, Wuhan 430072, China

2 Wuhan National Laboratory for Optoelectronics, School of Optoelectronic Science and Engineering, Huazhong University of Science and Technology, Wuhan 430074, China

*Corresponding authors (email: lizhen@whu.edu.cn; lei96wang@163.com)

Received May 9, 2013; accepted May 30, 2013; published online July 19, 2013

全文见: Huang J, Chen PY, Yang X, Tang RL, Wang L, Qin JQ, Li Z. Construction of deep-blue AIE luminogens with TPE and oxadiazole units. Sci China Chem, 2013, 56(9): 1213-1220

\begin{abstract}
In this paper, two AIE-active luminogens (Oxa-pTPE and Oxa-m $\boldsymbol{m}$ TPE) constructed from tetraphenylethene and oxadiazole units were successfully synthesized and their thermal, optical and electronic properties were investigated. By linking TPE to the oxadiazole core through meta- or para- position, the intramolecular conjugation is effectively controlled. Thanks to the intelligent molecular design and specific AIE feature, when fabricated as emissive layers in non-doped OLEDs, they exhibit blue or deep-blue emission with CIE coordinates of $(0.17,0.23)$ and $(0.15$, 0.12 ), and good efficiencies with $\eta_{\mathrm{C}, \max }$ and $\eta_{\mathrm{P}, \max }$ up to $1.52 \mathrm{~cd} \mathrm{~A}^{-1}$ and $0.84 \mathrm{Im} \mathrm{W}^{-1}$, shedding some light on the construction of deep-blue AIE fluorophores.
\end{abstract}

Keywords: aggregation-induced emission, tetraphenylethene, deep-blue emitter, organic light-emitting diodes

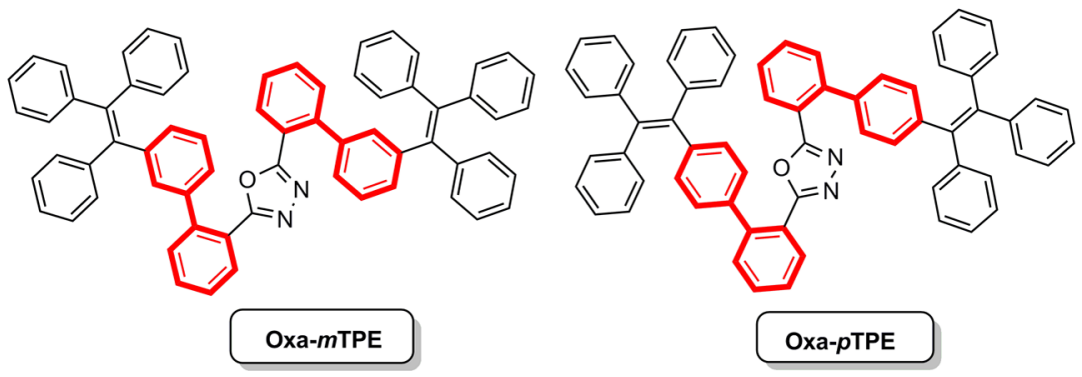

Chemical structures of Oxa- $m$ TPE and Oxa- $p$ TPE.

EL performances of Oxa- $p$ TPE and Oxa- $m \mathrm{TPE}^{\mathrm{a})}$

\begin{tabular}{ccccccc}
\hline & $V_{\text {on }}(\mathrm{V})$ & $L_{\max }\left(\mathrm{cd} \mathrm{m}^{-2}\right)$ & $\eta_{\mathrm{P}, \max }\left(\operatorname{Im~w}^{-1}\right)$ & $\eta_{\mathrm{C}, \max }\left(\mathrm{cd} \mathrm{A}^{-1}\right)$ & $\eta_{\mathrm{ext}, \max }(\%)$ & $\mathrm{CIE}(x, y)$ \\
\hline Oxa-p TPE & 5.10 & 615 & 0.84 & 1.52 & 0.97 & $0.17,0.23$ \\
Oxa-m $\boldsymbol{m}$ TPE & 6.25 & 750 & 0.49 & 0.72 & 0.82 \\
\hline
\end{tabular}

a) Abbreviations: $V_{\mathrm{on}}=$ turn-on voltage at $1 \mathrm{~cd} \mathrm{~m}^{-2}, L_{\mathrm{max}}=\operatorname{maximum}$ luminance, $\eta_{\mathrm{P}, \max }, \eta_{\mathrm{C}, \max }$ and $\eta_{\mathrm{ext} \text {, max }}=$ maximum power, current and external efficiencies, respectively. CIE = Commission International de l'Eclairage coordinates. 